\title{
The Impact of Wine Style and Sugar Addition in liqueur d'expedition (dosage) Solutions on Traditional Method Sparkling Wine Composition
}

\author{
Belinda Kemp ${ }^{1,2, *}$, Casey Hogan ${ }^{2}$, Shufen $\mathrm{Xu}{ }^{1}$, Lisa Dowling ${ }^{1}$ and Debbie Inglis ${ }^{1,2}$ \\ 1 Cool Climate Oenology and Viticulture Institute (CCOVI), Brock University, 1812 Sir Isaac Brock Way, \\ St Catharines, ON L2S 3A1, Canada; sxu@brocku.ca (S.X.); ldowling@brocku.ca (L.D.); \\ dinglis@brocku.ca (D.I.) \\ 2 Department of Biological Sciences, Faculty of Mathematics and Science, Brock University, \\ 1812 Sir Isaac Brock Way, St. Catharines, ON L2S 3A1, Canada; caseyrhogan@gmail.com \\ * Correspondence: bkemp@brocku.ca; Tel.: +1-905-688-5550
}

Academic Editor: Shao Quan Liu

Received: 13 December 2016; Accepted: 12 January 2017; Published: 18 January 2017

\begin{abstract}
The purpose of this study was to investigate the effect of wine style and cane sugar addition in the liqueur d'expedition (dosage) solution on volatile aroma compounds (VOCs) in traditional method sparkling wine. There were 24 bottles of each treatment produced. Treatments were sparkling wine zero dosage (ZD); NV sparkling wine + sugar (BS); unoaked still Chardonnay wine + sugar (UC); Pinot noir 2009 sparkling wine + sugar (PN); Niagara produced Brandy + sugar (B) and Icewine (IW). The control treatment in the sensory analysis was an oaked still Chardonnay wine + sugar (OC) because the zero-dosage wine was not suitable for a difference test that compared wines with sugar to one without. Standard wine chemical parameters were analysed before disgorging and after liqueur d'expedition was added and included; $\mathrm{pH}$, titratable acidity (TA $\mathrm{g} / \mathrm{L})$, alcohol $(v / v \%)$, residual sugar (RS g/L), free and total $\mathrm{SO}_{2}$ and total phenolics (A.U.). Volatile aroma compounds (VOCs) analysed by Headspace Solid- Phase Micro-Extraction Gas Chromatography-Mass Spectrometry (HS-SPME-GC-MS) included two alcohols, and six ethyl esters. ZD wines had the highest foam height and highest dissolved oxygen level. Sugar affected VOC concentrations in all treatments at five weeks post-disgorging, but by 15 weeks after liqueur d'expedition addition, the wine with added sugar had similar VOC concentrations to the ZD wines. The type of wines used in the dosage solutions had more influence on VOC concentrations than sugar addition.
\end{abstract}

Keywords: sparkling wine; liqueur d'expedition; volatile aroma compounds; foam

\section{Introduction}

Four main methods are used to produce sparkling wine: the Charmat/Cuvé closed/tank method; transfer method; carbonation of the base wine; and Methode Champenoise (in Champagne only), though it is are referred to as the Traditional Method, Classic method, Methode Traditionale or bottle-fermented in other parts of the world. Although the term bottle-fermented can also refer to the transfer method, in this study it refers to the Traditional Method whereby the second fermentation occurs in the bottle that is ultimately sold to consumers. There are two main production phases to Traditional Method sparkling winemaking as reviewed in Kemp et al. [1]: the first stage is the first fermentation of grape juice to convert it into base wine; the second stage is when the base wines go through a second fermentation in the bottle after the addition of yeast and sugar (liqueur de tirage). Following a period of aging on the yeast lees (sur lies), bottles are riddled to move the sediment to the neck. Yeast biomass is then expunged by freezing the lower part of the bottle's neck and removing the sediment. Prior to closing the bottle with a cork, dosage (liqueur d'expedition) is inserted into each bottle and determines the 
final sweetness of the wine as well as a consistency in winery style. The liqueur d'expedition is used to balance the wine and can also provide a wine with a unique flavour. Commonly referred to as dosage, it has been known to be produced using a range of sugar types (i.e., cane sugar, dextrose, beet sugar, liquid sugar or rectified concentrated grape must (RCGM)). Additionally, the wine used to make the dosage (+ / - sugar) can include the same wine as that being disgorged, another sparkling wine from the cellar, oaked or unoaked still wine or wines aged in stainless steel or oak barrels depending on the required wine style of the winemaker [1,2]. Sparkling wines that do not have sugar added and are topped up with the same wine as that in the bottle are referred to in literature as zero dosage, Brut Zero, Brut naturel, Nature $(<0.3 \%)$ or Extra Brut $(<0.6 \%)$. Although produced for many years, zero dosage wines have recently increased in popularity [3]. Bottle-fermented sparkling wines range in sugar levels with Brut wines tending to be adjusted with up to $1.5 w / v \%$ sugar, whereas Extra-sec generally contains $1.2 \%-2 \%$ sugar. Sec wines commonly have between $2 \%$ and $4 \%$ sugar, Demi-sec between 3\% and 5\% sugar and the now rare Doux wines contain more than 5\% sugar [3]. Residual sugar levels (RS g/L) are known to impact sparkling wine flavour but can cause an "unbalanced" wine if levels are too high or too low. Additionally, it was reported that sucrose strongly suppressed sourness in sparkling wines while subtly enhancing flavour [4].

The length of time between disgorging and release of sparkling wines from the winery is decided by the wine producer, but the flavour of sparkling wine after disgorging and dosage addition is known to continuously change. The influence of grape variety, lees aging and bottle aging post-disgorging on volatile aroma compounds (VOCs) and foam has been studied [5], but sparkling wines were analysed 12 months after disgorging and did not have sugar added (zero dosage wines topped with the same wine but without sugar addition). The authors of the manuscript reported that Albariño, Verdejo, Godello and Prieto Picudo were richest in most of the VOCs analysed, but Verdejo and Prieto Picudo had the best foam physiognomies. These characteristics were maintained during lees aging and in bottle after disgorging. However, to the authors' knowledge, no studies have investigated the impact of wine style or sugar addition used in the dosage on VOCs during bottle aging post-disgorging.

The disparity in the chemical nature and the concentrations of compounds in sparkling wines makes their analysis difficult [6]. Therefore, in this study, the focus was on eight VOCs at 5, 10 and 15 weeks after disgorging and dosage addition as well as standard chemical parameters, dissolved oxygen and foam. With the short growing season in Ontario, this study will show that dosage can also be used to create a unique product with complexity and flavour.

\section{Materials and Methods}

\subsection{Sparkling Wine Treatments}

The non-vintage (NV) sparkling wine was donated by Trius Winery, Niagara on-the-Lake, Ontario, Canada and disgorged on 26 February 2014 and analysed at 5, 10 and 15 weeks post-disgorging on 2 April, 7 May and 18 June 2014 respectively. The NV wine consisted of 70\% Chardonnay, $28 \%$ Pinot noir and 2\% Pinot Meunier. Of these, 42\% was from 2011, 25\% from 2010, 16\% from 2009, 13\% from 2008 and 4\% from 2007. The base wine was bottled for second fermentation in March 2012 and wines therefore had approximately 2 years of aging on yeast lees prior to disgorging. The oaked Chardonnay (OC) was from 2012 vintage and fermented and then aged in French oak barrels for 12 months, while the unoaked Chardonnay (UC) was from the 2013 vintage and fermented in stainless steel tanks. The brandy (B) was purchased from Forty Creek distillery in Niagara, Ontario, Canada and the Icewine (IW) was produced from Vidal grapes from the 2012 vintage and donated by Trius Winery. The oldest wine used in the study was the Blanc de noir 2009 produced from Pinot noir grapes and bottled in February 2010 with approximately 4 years in contact with yeast lees. All wines were analysed for chemical parameters according to Iland et al. [7] standard industry practices.

Sparkling wine dosage treatments were: NV sparkling wine without sugar addition but with addition of the same wines zero dosage (ZD); NV sparkling wine + sugar (BS); unoaked still Chardonnay 
wine + sugar (UC); Pinot noir 2009 sparkling wine + sugar (PN); Niagara produced Brandy + sugar (B); Icewine (IW). The control treatment in the sensory analysis was an oaked still Chardonnay wine + sugar (OC). Granulated cane sugar (Redpath Sugar Ltd., Toronto, ON, Canada) additions were; $\mathrm{ZD}=0 \mathrm{~g} / \mathrm{L}, \mathrm{BS}=299.6 \mathrm{~g} / \mathrm{L}, \mathrm{UC}=299 \mathrm{~g} / \mathrm{L}, \mathrm{OC}=273.1 \mathrm{~g} / \mathrm{L}, \mathrm{PN}=299.6 \mathrm{~g} / \mathrm{L}, \mathrm{IW}=76.8 \mathrm{~g} / \mathrm{L}$ and $\mathrm{B}=295.8 \mathrm{~g} / \mathrm{L}$. The control for chemical and volatile aroma analysis was $\mathrm{ZD}$ (without sugar) but the control for the sensory analysis was the OC because the composition of ZD without sugar addition made it unsuitable to be included in a difference test. After sugar addition, samples of each dosage were taken for standard wine chemical, and VOC analysis. Sulfur dioxide $\left(\mathrm{SO}_{2}\right)$ additions were made after analytical samples were taken to ensure each dosage had a free $\mathrm{SO}_{2}$ level of $900 \mathrm{mg} / \mathrm{L}$. Wines were analysed prior to, and after sugar addition to ensure a residual sugar level of $300 \mathrm{~g} / \mathrm{L}$ in the dosage solutions to reach a residual sugar (RS) level of $8 \mathrm{~g} / \mathrm{L}$ ( $\pm 2 \mathrm{~g} / \mathrm{L}$ ) in each $750 \mathrm{~mL}$ bottle. Wines were bottled at the same pressure 6 atmospheres (atm) and the dosage solution addition in each bottle was $20 \mathrm{~mL}$. Wines were disgorged by trained staff on a commercial disgorging line at Trius Winery, Niagara-on-the-Lake, Ontario and sealed with a cork closure and muselet (wire cage) before being transported immediately to the Cool Climate and Oenology Institute (CCOVI) at Brock University, Ontario. Prior to VOC analysis, wines were stored in a horizontal position in a specialised wine cellar at a temperature of $14{ }^{\circ} \mathrm{C}$ with a relative humidity of $70 \%$.

\subsection{Chemical Analyses}

The wine used to make the individual dosage solutions, final dosage solutions and the sparkling treatment wines after disgorging/dosage addition were analysed at 5, 10 and 15 weeks for standard wine chemical parameters. Three bottles of the control and treatment wines were analysed in triplicate for $\mathrm{pH}$, titratable acidity (TA g/L), alcohol $\left(v / v \%\right.$ ), residual sugar (RS g/L), free and total $\mathrm{SO}_{2}$ and total phenolics (A.U.) [7]. All wines were degassed at room temperature $\left(20^{\circ} \mathrm{C}\right)$ prior to chemical and sensory analysis. Degassing was carried out using a vacuum filtration system that included an EMD Millipore $90 \mathrm{~mm}$ Glass Vacuum Filter Holder with a borosilicate glass funnel, base, tubulated cap, a PTFE-coated stainless steel screen and an anodised aluminum spring clamp (Millipore Inc., Etobicoke, ON, Canada). For alcohol levels $(v / v \%)$, three bottles, each one measured in duplicate, were analysed by a modified-method from Nurgel et al. [8] using a Gas Chromatographer coupled to a Flame Ionisation Detector (GC-FID). Method modifications included the GC-FID (Agilent 6890, Agilent Inc., Santa Clara, CA, USA) equipped with a DB wax column, a 7683B injector and the internal standard was $0.1 \%$ butanol. Residual sugar $(\mathrm{g} / \mathrm{L}$ ) was analysed using an enzymatic kit (Megazyme, Chicago, IL, USA) and total phenolics was measured according to Iland et al. [7] by absorbance reading (A.U.) at $280 \mathrm{~nm}$. Dissolved oxygen $(\mathrm{mg} / \mathrm{L})$ levels in each treatment wine were analysed using a dissolved oxygen meter (DOM) from Hanna Instruments (Model 9146, Woonsocket, RI, USA).

\subsection{Reagents, Chemicals and Standards}

All volatile aroma compound standards and sparkling wine samples were prepared according to the method by Botezatu et al. [9]. Reference compounds and their suppliers can be found in Table 1. Milli-Q water was obtained from Biocel (Millipore Inc., Etobicoke, ON, Canada) and filtered through $0.22 \mu \mathrm{M}$ filter (Millipore, Canada). All stock standard solutions (standard A) were prepared using ethanol (Chromasolv ${ }^{\circledR}$ HPLC grade, Sigma-Aldrich, Oakville, ON, Canada). From standard A, a composite standard solution was made and labelled as standard $C$ which was used to prepare Standard $6^{\prime}$ as a working standard. Each reference compound was identified by their EI spectrum according to Enhanced ChemStation MSD (E.02.00.493)/Wiley spectral databases (NIST 08) and published literature. These compounds were also confirmed using qualifying and quantifying ions (Table 1). The purchased deuterated internal standards were analysed by EI-MS and matched to the GC-MS EI spectrum [9]. 
Table 1. List of volatile aroma compounds analysed, their aroma descriptors and odour thresholds.

\begin{tabular}{|c|c|c|c|c|c|}
\hline Aroma Compound & Aroma Descriptors & $\begin{array}{l}\text { Odor Threshold } \\
(\mu \mathrm{g} / \mathrm{L})\end{array}$ & $\begin{array}{l}\text { Purity } \\
(\%)\end{array}$ & CAS No. & Supplier \\
\hline d11 Ethyl hexanoate ISTD & N/A & N/A & 98.7 & $2159-19-5$ & $\begin{array}{c}\text { CDN Isotopes, } \\
\text { Pointe-Claire, } \\
\text { QC, Canada }\end{array}$ \\
\hline \multicolumn{6}{|c|}{ Ethyl ester: Linear fatty acid derivatives } \\
\hline Ethyl octanoate & Fruity, apricot, pineapple & $580^{\mathrm{a}}$ & $>99$ & $106-32-1$ & Sigma Aldrich \\
\hline Ethyl hexanoate & Apple, blackberry & $62^{d}$ & 99 & $123-66-0$ & Sigma Aldrich \\
\hline Ethyl butanoate & $\begin{array}{l}\text { Acid fruit, candy, } \\
\text { strawberry }\end{array}$ & $20^{\mathrm{b}}$ and $125^{\mathrm{d}}$ & 99 & $105-54-4$ & Sigma Aldrich \\
\hline \multicolumn{6}{|c|}{ Ethyl esters: Branched acid derivatives } \\
\hline Ethyl isobutyrate & $\begin{array}{l}\text { Apple, citrus, } \\
\text { tropical fruit }\end{array}$ & $15^{c}$ & 99 & $97-62-1$ & Sigma Aldrich \\
\hline Ethyl isovalerate & Mint, fruit & $3^{c}$ & 98 & $108-64-5$ & Sigma Aldrich \\
\hline Ethyl-2-methylbutyrate & Sweet fruit & $18^{\mathrm{c}}$ & 99 & $7452-79-1$ & Sigma Aldrich \\
\hline \multicolumn{6}{|c|}{ Alcohols } \\
\hline 2-Phenylethanol & Roses & $14,000^{\mathrm{c}}$ & 99 & $60-12-8$ & Sigma Aldrich \\
\hline 1-Hexanol & Herbal, green, grass & $8000^{\mathrm{b}}$ & 99.5 & $111-27-3$ & Sigma Aldrich \\
\hline
\end{tabular}

${ }^{a}$ Etiévant [10], odour thresholds determined in wine; ${ }^{b}$ Guth et al. [11], odour thresholds determined in $10 \%$ ethanol/water solution; ${ }^{\mathrm{c}}$ Ferreira et al. [12], odour thresholds determined in $10 \%$ ethanol/water solution with $7 \mathrm{~g} / \mathrm{L}$ glycerol at $\mathrm{pH} 3.2{ }^{\mathrm{d}}{ }^{\mathrm{S}}$ San Juan et al.[13] odour threshold determined in $10 \%$ ethanol/water solution at $\mathrm{pH} 3.2$.

\subsection{Sample Preparation of Wines for Volatile Aroma Compound (VOC) Analyses}

Samples were prepared according to Botezatu et al. [9]. To a $20 \mathrm{~mL}$ amber round-bottomed glass vial, $3 \mathrm{~g} \mathrm{NaCl}$ and a stir bar were added, followed by $8.06 \mathrm{~mL}$ of Milli-Q and $0.90 \mathrm{~mL}$ of wine for a 10 -fold dilution. Finally, $40 \mu \mathrm{L}$ of the deuterated internal standard ethyl hexanoate-d11 standard $\mathrm{C}$ was added and the vial was closed with magnetic screw cap immediately. The final dilution for the wine for VOC analysis was 10-fold. Samples were incubated at $40{ }^{\circ} \mathrm{C}$ and stirred at $600 \mathrm{rpm}$ for $1 \mathrm{~min}$ before being exposed to the fiber for $30 \mathrm{~min}$ at $40^{\circ} \mathrm{C}$ with stirring at $600 \mathrm{rpm}$.

\subsection{Preparation of Volatile Aroma Compound (VOC) Standards}

Volatile aroma standards were prepared according to Botezatu et al. [9]. To a $20 \mathrm{~mL}$ round-bottomed amber glass vials (MicroLiter, Millville, NJ, USA), $3 \mathrm{~g}$ of reagent grade $\mathrm{NaCl}$ (Bioshop, Burlington, ON, Canada) and a stir bar were added, then $8.06 \mathrm{~mL}$ of Milli-Q water and the matrix (14\% hydro-ethanolic solution) and composite standards as indicated in Table 1 . A volume of $40 \mu \mathrm{L}$ of ethyl hexanoate- $\mathrm{d}_{11}$ solution $C$ was added and the vial was capped with a magnetic screw/thread headspace cap PTFE/silicone (MicroLiter, Millville, NJ, USA) immediately.

\subsection{Headspace Solid-Phase Micro-Extraction Gas Chromatography-Mass Spectrometry (HS-SPME-GC-MS)}

The HS-SPME-GC-MS method from Botezatu et al. [9] was used to analyse VOCs. A $2 \mathrm{~cm}$ divinylbenzene/carboxen/polydimethylsiloxane (DVB/CAR/PDMS) (Supelco Inc., Bellefonte, PA, USA), 23 gauge SPME fiber was used for sampling. Samples were incubated at $40{ }^{\circ} \mathrm{C}$ with a conditioned stir bar before exposing the fiber for $30 \mathrm{~min}$ at $40{ }^{\circ} \mathrm{C}$ at $600 \mathrm{rpm}$. The samples were analysed using an Agilent (Mississauga, ON, Canada) 7890A gas chromatograph coupled to a 5975C mass selective detector (MSD) equipped with a Gerstal MPS2 XL autosampler (Linthicum Heights, MD, USA). The GC was equipped with a Deans Switch and two columns: a HP-5MS 5\% phenyl methyl siloxane column (30 m, $0.25 \mathrm{~mm}$ i.d., $0.25 \mu \mathrm{m}$ film thickness) coupled with a secondary DB-Wax capillary column (30 m, $0.25 \mathrm{~mm}$ i.d., $0.25 \mu \mathrm{m}$ film thickness) (Agilent Technologies Inc., Santa Clara, CA, USA) . The liner was a SPME inlet liner ( $0.7 \mathrm{~mm}$ i.d.; Supelco). Helium was used as the carrier gas with a flow rate of $0.5 \mathrm{~mL} / \mathrm{min}$ in the first column, and $1.5 \mathrm{~mL} / \mathrm{min}$ in the second column. Oven temperature programming began at $35^{\circ} \mathrm{C}$ for $3 \mathrm{~min}$, and then increased $3{ }^{\circ} \mathrm{C} / \mathrm{min}$ up to $105^{\circ} \mathrm{C}$ where it was held for $10 \mathrm{~min}$. Temperature was then increased by $2{ }^{\circ} \mathrm{C} / \mathrm{min}$ up to $140{ }^{\circ} \mathrm{C}$, before holding for $10 \mathrm{~min}$. 
Temperature went through one more ramp up of $4{ }^{\circ} \mathrm{C} / \mathrm{min}$ up to $250{ }^{\circ} \mathrm{C}$, before holding for a final $10 \mathrm{~min}$. The run time for this method was $101 \mathrm{~min}$. The MSD interface was held at $250{ }^{\circ} \mathrm{C}$. The inlet temperature was $250^{\circ} \mathrm{C}$ and the SPME fiber was desorbed in splitless mode. The solvent delay was $5 \mathrm{~min}$. The fiber was prebaked for $10 \mathrm{~min}$ and post baked for $20 \mathrm{~min}$. Samples were warmed at $40{ }^{\circ} \mathrm{C}$ and stirred at $600 \mathrm{rpm}$ for $1 \mathrm{~min}$ before being exposed to the fiber for $30 \mathrm{~min}$ at $40{ }^{\circ} \mathrm{C}$ with stirring at $600 \mathrm{rpm}$, followed by desorption in the inlet for $10 \mathrm{~min}$. Electron ionisation source was used, with a source temperature of $230^{\circ} \mathrm{C}$ and electron energy of $-70 \mathrm{eV}$. The samples were measured using synchronous scan and selected ion monitoring (SIM mode). The scan parameters ran from $35 \mathrm{~m} / \mathrm{z}$ to $400 \mathrm{~m} / \mathrm{z}$, and both scan and SIM acquisitions were performed with an EMV Gain Factor of 7 . All analyses were carried out in duplicate.

\subsection{Data Processing of Volatile Aroma Compounds (VOCs)}

VOCs were identified according to Botezatu et al. [9] using the ChemStation MSD (E.02.00.493) by Agilent, in addition to their authentic standards and concentrations found in current literature. The quantifying ions (Table 2) were extracted, and the ratio of the standard over the internal standard was plotted against the concentration of the VOC to fit a linear equation where the intercept was set to zero. Spiked samples were prepared to calculate the percent of recovery.

Table 2. Summary of parameters for volatile aroma compound quantification.

\begin{tabular}{ccccc}
\hline Volatile Aroma Compound & Retention Time (mins) & Target Ions (m/z) & Confirming Ions (m/z) & Standard Curve $\left.\mathbf{( R}^{\mathbf{2}}\right)$ \\
\hline Ethyl hexanoate-d11-IS & 26 & 91 & 50,110 & - \\
\hline \multicolumn{5}{c}{ Ethyl esters: Linear fatty acid derivatives } \\
\hline Ethyl butanoate & 15.77 & 88 & 101,60 & 0.9774 \\
Ethyl hexanoate & 26.8 & 88 & 115,60 & 0.9746 \\
Ethyl octanoate & 41.31 & 88 & 0.9936 \\
\hline \multicolumn{5}{c}{ Ethyl esters: Branched acid derivatives } \\
\hline Ethyl Isobutyrate & 11,243 & 71,116 \\
Ethyl isovalerate & 13.57 & 881.3 & 85,130 & 0.9954 \\
Ethyl 2-methylbutyrate & 18.39 & 57,229 & 102,130 & 0.9832 \\
\hline \multicolumn{5}{c}{} \\
\hline 1-Hexanol & 18.82 & Alcohols \\
2-Phenylethanol & 22.87 & 56 & 55,84 \\
\hline
\end{tabular}

\subsection{Foam Analyses}

Foam analysis was carried out using a video technique by Lynch and Bamford [14] with beer and Curioni et al. [15] with sparkling wine. Along with a timer, a high quality digital SLR camera with video capability (Canon EOS 70D, Canon Canada Inc., Mississauga, ON, Canada,) was used with a $250 \mathrm{~mL}$ glass volumetric cylinder free of scratches, faults, or marks. Each wine was opened and a waiting period of five minutes prior to pouring was imposed to reduce variability between samples. Once filming commenced, the bottle was held at a $45^{\circ}$ angle and wine was poured into the top of the $250 \mathrm{~mL}$ volumetric cylinder and monitored until all foam diffused. The resultant film was analysed using Windows Media Player recording the time it took for the dissipation of foam (FDsec), the foam height between top of the foam and the underlying wine immediately upon pouring ( $\mathrm{FHcm}$ ), and the volume of the underlying wine after the foam had dissipated $(\mathrm{mL})$. The room temperature was $20^{\circ} \mathrm{C}$ and wines ranged in temperature from $18.5^{\circ} \mathrm{C}$ to $19^{\circ} \mathrm{C}$ to be close to the room temperature to avoid loss through gushing.

\subsection{Sensory Analysis}

Except for ZD wine, all wines were analysed using the A-Not A difference test [16]. The ZD wine was deemed unsuitable to include in a difference test because of a lack of sugar addition that would skew results. The A-Not A difference test can be superior to the triangle test, duo-trio 
test, and same-difference test in terms of statistical power [17]. It is used to measure the overall sensory difference of one or more products from a reference sample A (OC—control) using a sureness rating $[17,18]$. Participants were asked to state on ballot papers whether the sample poured was A or, not A. The sureness rating was included to minimise the response bias of assessors. In this study, participants were asked to indicate how sure they were about their decision using a simple scale of very sure, sure, unsure and very unsure [19]. The sureness rating for " $A$ " and for "Not $A$ " responses were analysed using the $R$-index which represents the probability of participants distinguishing between the wines tasted $[19,20]$.

The sensory panel consisted of 16 participants that included 13 Niagara winemakers and 3 oenology postgraduate students (10 males and 6 females), following ethics approval from the Research Ethics Board at Brock University (file \#14-03) with clearance granted from 9/5/2014 to $9 / 30 / 2015$. The sensory session began when wines $(50 \mathrm{~mL})$ were poured into clear ISO wine glasses and participants were asked to familiarise themselves with the wines retronasally. To improve the panelists' overall sensory perception of samples, a familiarisation session took place [17]. After $20 \mathrm{~min}$ of familiarising themselves with the wines, panelists had a 20-minute break and cleansed their palates with distilled water and unsalted crackers. All wine glasses were assigned a 3-digit number specific to each wine treatment and to each participant. Participants were also assigned 3-digit numbers to ensure anonymity. Following the familiarisation session, the A-Not A test was carried out according to Kemp et al. [19]. The wines were served in a randomised order per participant and no two assessors had the same order of wines. Each participant consumed unsalted crackers and distilled water between sample pairs. All treatment wines were tasted in duplicate to allow for sparkling wine bottle variation. Compusense 5.2 (Compusense, Guelph, ON, Canada) was used for responses. The room temperature was $20^{\circ} \mathrm{C}$ with continuous airflow to prevent air contamination.

\subsection{Statistical Analysis}

Analysis of Variance (ANOVA), Tukey's Post-hoc test, Principal Component Analysis (PCA), Chi-squared test $\left(\chi^{2}\right)$, and standard deviations were calculated using XLSTAT Version 2014 software (Addinsoft, Paris, France). The $R$-index was calculated according to Kemp et al. [19].

\section{Results and Discussion}

\subsection{Chemical Analyses}

\subsubsection{Chemical Parameters of the Wines Used as Dosage Bases before Sugar Addition}

There was a statistically significant difference $(p=0.001)$ for all chemical parameters analysed between the wines that were used for making the dosage solutions (Table 3). B had the highest $\mathrm{pH}$, alcohol and lowest acidity while PN had the highest acidity and the IW had the lowest alcohol level due to their respective methods of production. Residual sugar (RS g/L) levels were found to be highest in IW due to the fact that yeast only consume approximately half the juice sugar during fermentation with a legal requirement for Icewines to have a minimum residual sugar of $125 \mathrm{~g} / \mathrm{L}$. The lowest RS was found in the NV and Pinot noir wines likely due to completion of secondary fermentation in bottle. The highest free and total $\mathrm{SO}_{2}$ was found in $\mathrm{OC}$ because $\mathrm{SO}_{2}$ had already been added by the winery as part of the preparation for the dosage solution. The lowest free and total $\mathrm{SO}_{2}$ was observed in the brandy. Total phenolic compounds were highest in OC wine (12 A.U.) and lowest in the NV sparkling wine (4.4 A.U.). No differences in total phenolic compounds in Charmat (secondary fermentation in tank) wines (Pinot noir (48\%), Chardonnay (10\%) and Riesling $(42 \%)$ ) when sugar was added at rates of $10 \mathrm{~g} / \mathrm{L}, 20 \mathrm{~g} / \mathrm{L}$ and $30 \mathrm{~g} / \mathrm{L}$ was reported by Stefenon et al. [21]. These contradictory results could be attributed to the higher levels of phenolic compounds in the wines used as the base for dosages in our study, different analytical methods in the two studies and/or different sparkling wine production techniques used in each study. 
Table 3. Chemical analyses of the wines used for dosage prior to sugar addition.

\begin{tabular}{|c|c|c|c|c|c|c|}
\hline Chemical Analysis & NV Sparkling & $\begin{array}{c}\text { Oaked } \\
\text { Chardonnay }\end{array}$ & $\begin{array}{c}\text { Unoaked } \\
\text { Chardonnay }\end{array}$ & $\begin{array}{c}\text { Pinot Noir } \\
2009\end{array}$ & $\begin{array}{c}\text { Vidal } \\
\text { Icewine }\end{array}$ & Brandy \\
\hline $\mathrm{pH}$ & $3.10 \pm 0.01^{\mathrm{e}}$ & $3.32 \pm 0.01^{\mathrm{d}}$ & $3.4 \pm 0.01^{c}$ & $3.1 \pm 0.01^{\mathrm{e}}$ & $3.6 \pm 0.01^{b}$ & $3.9 \pm 0.02^{a}$ \\
\hline $\mathrm{TA}(\mathrm{g} / \mathrm{L})$ & $8.40 \pm 0.1^{b}$ & $4.50 \pm 0.1^{\mathrm{d}}$ & $6.5 \pm 0.1^{c}$ & $9.2 \pm 0.1^{\mathrm{a}}$ & $8.2 \pm 0.1^{b}$ & $0.2 \pm 0.20^{\mathrm{e}}$ \\
\hline Residual sugar (g/L) & $0.40 \pm 0.1^{b}$ & $26.9 \pm 2.6^{b}$ & $1.0 \pm 0.1^{b}$ & $0.4 \pm 0.1^{\mathrm{b}}$ & $223 \pm 15.4^{\mathrm{a}}$ & $4.2 \pm 0.10^{b}$ \\
\hline Alcohol $(\% v / v)$ & $12.30 \pm 0.1^{\mathrm{d}}$ & $12.8 \pm 0.1^{\mathrm{c}}$ & $13.1 \pm 0.1^{b}$ & $12.3 \pm 0.1^{\mathrm{d}}$ & $10.5 \pm 0.1^{\mathrm{e}}$ & $38.8 \pm 0.10^{a}$ \\
\hline Free $\mathrm{SO}_{2}(\mathrm{ppm})$ & $8.00 \pm 1.0^{b}$ & $864 \pm 42^{\mathrm{a}}$ & $41 \pm 3^{b}$ & $5 \pm 1^{b}$ & $60 \pm 1^{b}$ & $6 \pm 1.00^{\mathrm{b}}$ \\
\hline Total $\mathrm{SO}_{2}(\mathrm{ppm})$ & $64.00 \pm 2.1^{\mathrm{d}}$ & $959 \pm 14^{\mathrm{a}}$ & $139 \pm 6^{c}$ & $55 \pm 2^{d}$ & $477 \pm 25^{b}$ & $7 \pm 1.00^{\mathrm{e}}$ \\
\hline Total phenolics (A.U.) & $4.40 \pm 0.7^{\mathrm{d}}$ & $12 \pm 0.89^{a}$ & $5.3 \pm 0.09^{d}$ & $7.4 \pm 0.10^{\mathrm{c}}$ & $8.4 \pm 0.10^{c}$ & $10.5 \pm 0.39^{b}$ \\
\hline
\end{tabular}

All values are representative means of triplicate measurements ( $\pm=$ standard deviation of the means). ND $=$ not detected and \pm represents the standard deviation. Means identified by different letters were significantly different as determined by the post-hoc Tukey's test at $p<0.05$.

\subsubsection{Chemical Parameters of Wines at 15 Weeks after Dosage Addition}

Treatment wines, after dosage addition, were analysed for their standard chemical parameters at 5, 10 and 15 weeks after dosage addition (Table 4 and supplementary data). Only chemical data at 15 weeks is presented here (Table 4). Wines that had dosage solution made from sparkling wines all had higher $\mathrm{pH}$ levels than those dosage solutions made from still wine additions. There was no difference in acidity (TA g/L) between treatment wines and, as expected, the ZD wine had low levels of residual sugar compared to the other wines. Alcohol level was highest in B due to the higher alcohol level in the brandy compared to the other treatments. The chemical composition of the wines that were used to make the dosage solutions before sugar addition were statistically significant $(p<0.05)$ probably due to their diverse production methods. However, the wines after dosage addition at 5, 10 and 15 weeks showed no difference in titratable acidity (TA g/L).

Table 4. Chemical analyses of treatment wines 15 weeks after disgorging with dosage addition.

\begin{tabular}{|c|c|c|c|c|c|c|c|}
\hline Chemical Analysis & BS & ZD & OC & UC & PN & IW & B \\
\hline $\mathrm{pH}$ & $3.20 \pm 0.02^{a}$ & $3.35 \pm 0.02^{b}$ & $3.09 \pm 0.01^{c}$ & $3.09 \pm 0.01^{c}$ & $3.31 \pm 0.01^{\mathrm{a}}$ & $3.08 \pm 0.01^{\mathrm{c}}$ & $3.09 \pm 0.01^{\mathrm{c}}$ \\
\hline $\mathrm{TA}^{\mathrm{I}}(\mathrm{g} / \mathrm{L})$ & $8.2 \pm 0.1^{\mathrm{a}}$ & $8.2 \pm 0.1^{\mathrm{a}}$ & $8.0 \pm 0.1^{\mathrm{a}}$ & $7.9 \pm 0.1^{a}$ & $8.0 \pm 0.1^{\mathrm{a}}$ & $8.2 \pm 0.2^{\mathrm{a}}$ & $7.9 \pm 0.1^{\mathrm{a}}$ \\
\hline Residual sugar (g/L) & $7.6 \pm 0.1^{\mathrm{a}}$ & $1.1 \pm 0.1^{\mathrm{d}}$ & $7.5 \pm 0.2^{\mathrm{a}, \mathrm{b}}$ & $7.7 \pm 0.3^{a}$ & $7.1 \pm 0.1^{\mathrm{a}, \mathrm{b}}$ & $6.3 \pm 0.1^{c}$ & $7.0 \pm 0.3^{b}$ \\
\hline Alcohol $(\% v / v)$ & $12.4 \pm 0.1^{\mathrm{b}}$ & $12.3 \pm 0.1^{b}$ & $12.4 \pm 0.1^{\mathrm{b}}$ & $12.3 \pm 0.1^{b}$ & $12.3 \pm 0.1^{b}$ & $12.3 \pm 0.1^{b}$ & $12.9 \pm 0.1^{\mathrm{a}}$ \\
\hline Free $\mathrm{SO}_{2}(\mathrm{ppm})$ & $5 \pm 1^{\mathrm{a}, \mathrm{b}}$ & $4 \pm 1^{b}$ & $5 \pm 1^{\mathrm{a}, \mathrm{b}}$ & $3 \pm 1^{a}$ & $4 \pm 1^{b}$ & $4 \pm 1^{b}$ & $4 \pm 1^{\mathrm{b}}$ \\
\hline Total $\mathrm{SO}_{2}(\mathrm{ppm})$ & $54 \pm 12^{a, b}$ & $49 \pm 6^{a, b}$ & $59 \pm 7^{a}$ & $52 \pm 1^{\mathrm{a}, \mathrm{b}}$ & $48 \pm 2^{b}$ & $46 \pm 1^{b}$ & $53 \pm 2^{a, b}$ \\
\hline Total phenolics (A.U.) & $1.4 \pm 0.2^{\mathrm{a}, \mathrm{b}}$ & $1.5 \pm 0.2^{b}$ & $1.8 \pm 0.1^{\mathrm{a}, \mathrm{b}}$ & $1.3 \pm 0.1^{b}$ & $1.8 \pm 0.3^{\mathrm{a}, \mathrm{b}}$ & $1.6 \pm 0.1^{\mathrm{a}, \mathrm{b}}$ & $2.1 \pm 0.1^{\mathrm{a}}$ \\
\hline
\end{tabular}

All values are representative means of triplicate measurements ( $t=$ standard deviation of the means). ND = not detected and \pm represents the standard deviation. Means identified by different letters were significantly different as determined by the post-hoc Tukey's test at $p<0.05$. NV sparkling wine + sugar (BS); NV sparkling wine zero dosage (ZD); oaked still Chardonnay wine + sugar (OC); unoaked still Chardonnay wine + sugar (UC); Pinot noir 2009 sparkling wine + sugar (PN); Icewine (IW) and Brandy + sugar (B).

\subsubsection{Dissolved Oxygen}

The two highest levels of dissolved oxygen (DO) were found in the both NV wines (ZD and BS), which suggests that these wines were more susceptible to oxidation than the other treatment wines. The lowest level was found in IW while the highest was in ZD $(6.6 \mathrm{mg} / \mathrm{L})$. ZD might have had less protection against oxidation than wines with sugar addition. The next highest $\mathrm{DO}$ was found in the BS at $5.0 \mathrm{mg} / \mathrm{L}$, then UC $(4.6 \mathrm{mg} / \mathrm{L}), \mathrm{OC}(4.4 \mathrm{mg} / \mathrm{L}), \mathrm{B}(3.6 \mathrm{mg} / \mathrm{L}), \mathrm{PN}(3.5 \mathrm{mg} / \mathrm{L})$, and the lowest level was in IW $(3.1 \mathrm{mg} / \mathrm{L})$.

\subsection{Volatile Aroma Compounds (VOCs) in the Wines}

Unsurprisingly, there were differences in the concentrations of VOCs across all wines used for the dosage solutions before sugar was added to them. B had the highest levels of ethyl ester linear fatty acid derivatives; ethyl hexanoate and ethyl octanoate, as well as an alcohol, 1-hexanol, but it also had the lowest concentration of 1-phenylethanol. Of the ethyl ester branched acid derivatives, ethyl 
isobutyrate was found to be highest in $\mathrm{PN}$, and ethyl isovalerate highest in the NV sparkling wine that was the wine all dosage solutions were added to but also used in two treatments (ZD and BS). The OC wine had the highest ethyl butanoate and 1-phenylethanol while the UC wine had the lowest concentration of 1-hexanol. Vidal Icewine had the lowest ethyl butyrate and Pinot noir 2009 had the lowest ethyl hexanoate and ethyl octanoate, possibly due to longer lees aging than the other wines, but the highest ethyl-2-methylbutyrate.

\subsection{Volatile Aroma Compounds (VOCs) in the Dosage Solutions}

No discernible trend could be observed within families of VOCs in the BS compared to the ZD although some differences in several VOC concentrations were observed between them (Figure 1). ZD dosage solution had higher levels of ethyl isobutyrate, ethyl-2-methylbutyrate, ethyl isovalerate, ethyl hexanoate and 2-phenylethanol compared to BS. Although the BS dosage had higher ethyl butanoate, ethyl octanoate and 1-hexanol compared to the ZD so the addition of sugar increased some compounds but decreased others.

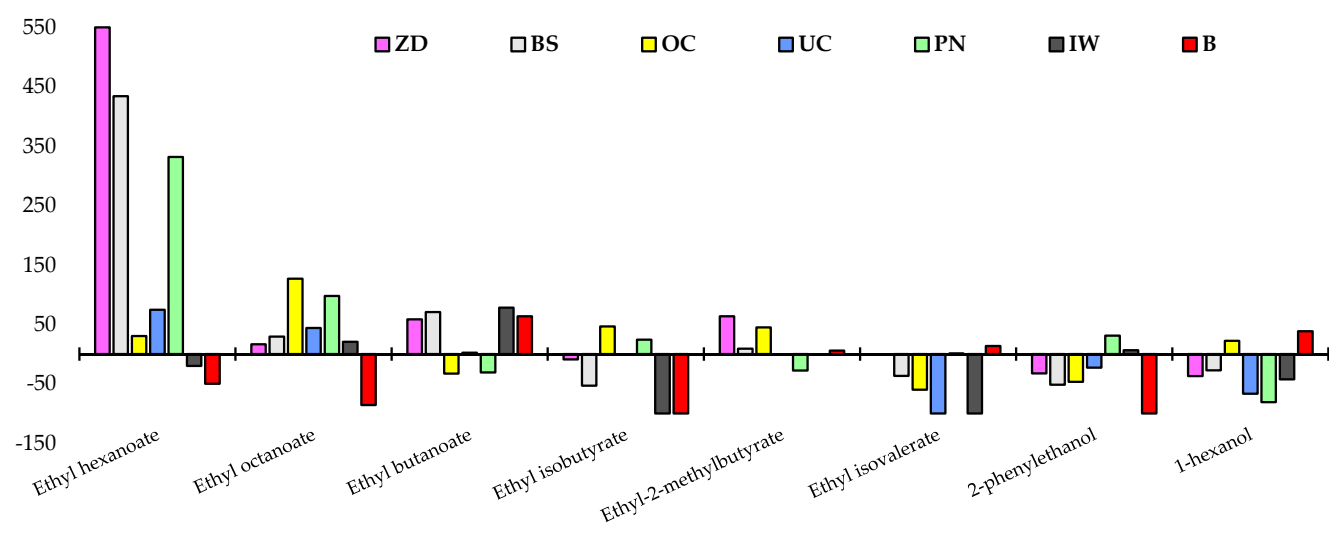

Figure 1. The increases and decreases of the mean concentrations (\%) of each volatile aroma compound (VOC) between wines used for the dosage solutions. NV sparkling wine without sugar addition = zero dosage (ZD), NV sparkling wine + sugar (BS), unoaked still Chardonnay wine + sugar (UC), Pinot noir 2009 sparkling wine + sugar (PN), Brandy + sugar (B), Icewine (IW) + sugar and oaked still Chardonnay wine + sugar (OC).

Ethyl hexanoate increased in all dosage solutions except in B and IW, with the biggest increase found in ZD which did not have sugar added, although this change might have been due to bottle variation or oxygen ingress at disgorging. There was no 2-Phenylethanol detected in the $\mathrm{B}$ dosage solution even though prior to sugar addition it had a concentration of $5842 \mu \mathrm{g} / \mathrm{L}$ which is likely due to sugar addition at $300 \mathrm{~g} / \mathrm{L}$ added to the high alcohol medium. Ethyl octanoate also increased in all dosage solutions except for B, whereas Ethyl butanoate decreased in PN and OC but not the other dosages. Ethyl isobutyrate only increased in PN and OC and decreased in the other dosages. Ethyl-2-methylbutyrate decreased in PN and increased in the other wines, but was not detected in UC. Ethyl isobutyrate, and ethyl isovalerate were not detected in UC and IW dosage solutions and ethyl isobutyrate was also not detected in B dosage solution. These results suggest that at levels of $300 \mathrm{~g} / \mathrm{L}$ residual sugar in the actual liqueur d'expedition before its addition to each individual wine bottle, ethyl ester branched acid derivatives were negatively impacted in some wines. For 1-hexanol, it decreased in all dosage solutions except for B and OC, whereas 2-phenylethanol decreased in all dosages except for $\mathrm{PN}$, and a very small (7\%) increase in IW.

Upon comparison of BS and ZD, ethyl hexanoate increased in both dosage solutions along with ethyl octanoate, ethyl butanoate and ethyl 2-methylbutyrate and a decrease was observed in both treatments for ethyl isobutyrate, ethyl isovalerate, 2-phenylethanol and 1-hexanol. VOCs were affected similarly for both NV dosage solutions except that BS had higher percent of increase, and decrease of 
compounds, except for ethyl hexanoate and ethyl-2-methyl butyrate which had higher percent increase in ZD than BS. The most likely explanation for the lack of specific trends in the decline and escalation of VOC concentrations in the dosage solutions is the physio-chemical composition of the wines, diverse grape varieties, and the range of wine styles, aging time and differences in production techniques of the wines used in the dosage solutions [22].

\subsection{Volatile Aroma Compounds (VOCs) in Wines at 5, 10 and 15 Weeks Post-Disgorging}

All wines were analysed for 8 VOCs ( 6 ethyl esters and 2 alcohols) over 15 weeks after disgorging, sugar addition and closure with cork. This section explains VOC differences in treatment wines over 15 weeks.

\subsection{Five Weeks Post-Disgorging}

At 5 weeks post-disgorging, BS had lower levels of alcohols than ZD. It was also higher in ethyl hexanoate and ethyl butanoate but lower in ethyl octanoate and ethyl isobutyrate than ZD (Table 5). All VOC concentrations in the treatment wines, except ethyl butanoate, were found to be significantly different statistically $(p<0.05)$ at 5 weeks post-disgorging. Ethyl-2-methylbutyrate was not detected in BS but was reported in Chardonnay sparkling wine enriched with glycosylated precursors at $3.3 \mu \mathrm{g} / \mathrm{L}$ even though in the German study sugar was not added after disgorging [23]. Differences in VOCs found in ZD compared to BS were detected in small concentrations at 5 weeks' post-disgorging which suggests that at levels of $8 \mathrm{~g} / \mathrm{L}( \pm 2)$ residual sugar, concentrations of alcohols and some ethyl ester branched acid derivatives were impacted. At this stage, ethyl isovalerate and ethyl hexanoate were found to be lower in ZD than BS. However, the introduction the dosage solution (+sugar) into the bottles increased ethyl isobutyrate, ethyl isovalerate, and ethyl hexanoate, whereas BS had the lowest ethyl octanoate. The high concentration of 2-phenyethanol (fermentation/yeast-derived VOC) in OC was likely due to extraction from oak during the production process of the wine used in the dosage solution [24]. UC had the lowest 1-hexanol and B had the lowest 2-phenylethanol. The leaf aldehyde, 1-hexanol, was found in the highest concentration in B, likely due to high concentrations in the brandy from the production method, and/or due to the ripeness level of the base material. Additionally, B had the lowest concentration of 2-phenylethanol.

$\mathrm{PN}$ wines had the highest ethyl isobutyrate, ethyl-2-methylbutyrate, and ethyl isovalerate, though the lowest ethyl hexanoate concentration. IW was found to have the lowest concentrations of ethyl isobutyrate, ethyl butanoate and ethyl-2-methylbutyrate. BS had the lowest ethyl octanoate and UC the lowest ethyl isovalerate. IW was found to have the lowest concentrations of ethyl isobutyrate, ethyl butanoate, ethyl-2-methylbutyrate and 1-hexanol.

Interestingly, B had the highest concentration of 4 of the 8 VOCs analysed: ethyl butanoate, ethyl hexanoate, ethyl octanoate and 1-hexanol. Of the monocarboxylic acid esters, the most important in brandy are those based on ethanol and saturated carboxylic acids, such as hexanoic (caproic), octanoic (caprylic) and decanoic (capric) acids [25]. In our study, the ranges of ethyl hexanoate and ethyl octanoate were 132-1687 $\mu \mathrm{g} / \mathrm{L}$ and 349-23,429 $\mu \mathrm{g} / \mathrm{L}$, respectively, with B having the highest concentration of both compounds. Our results for these compounds are higher than those reported in Cava wines (produced from Chardonnay grapes), which is most likely due to the inclusion of brandy in one of our treatment wines [26]. However, it is unclear in the study as to whether a sugar dosage solution was added to the Cava wines. It is important to state that previous studies of sparkling wine VOCs have focused on base wines, aged wines, vineyard soil types, and grape maturity [26-29]. Few peer-reviewed studies on sparkling wines have stated the ingredients of the dosage solution, the time after disgorging that the VOC analysis took place or have examined sparkling wine aroma development post-dosage addition. Although Pérez-Magariño et al. [5] analysed VOCs in sparkling wines at 12 months post-disgorging, the wines did not have a sugar addition after disgorging (zero dosage), and were also produced from varieties not included in our study. 
Table 5. Concentration of volatile aroma compounds (VOCs) in sparkling wines at 5,10 and 15 weeks post-disgorging.

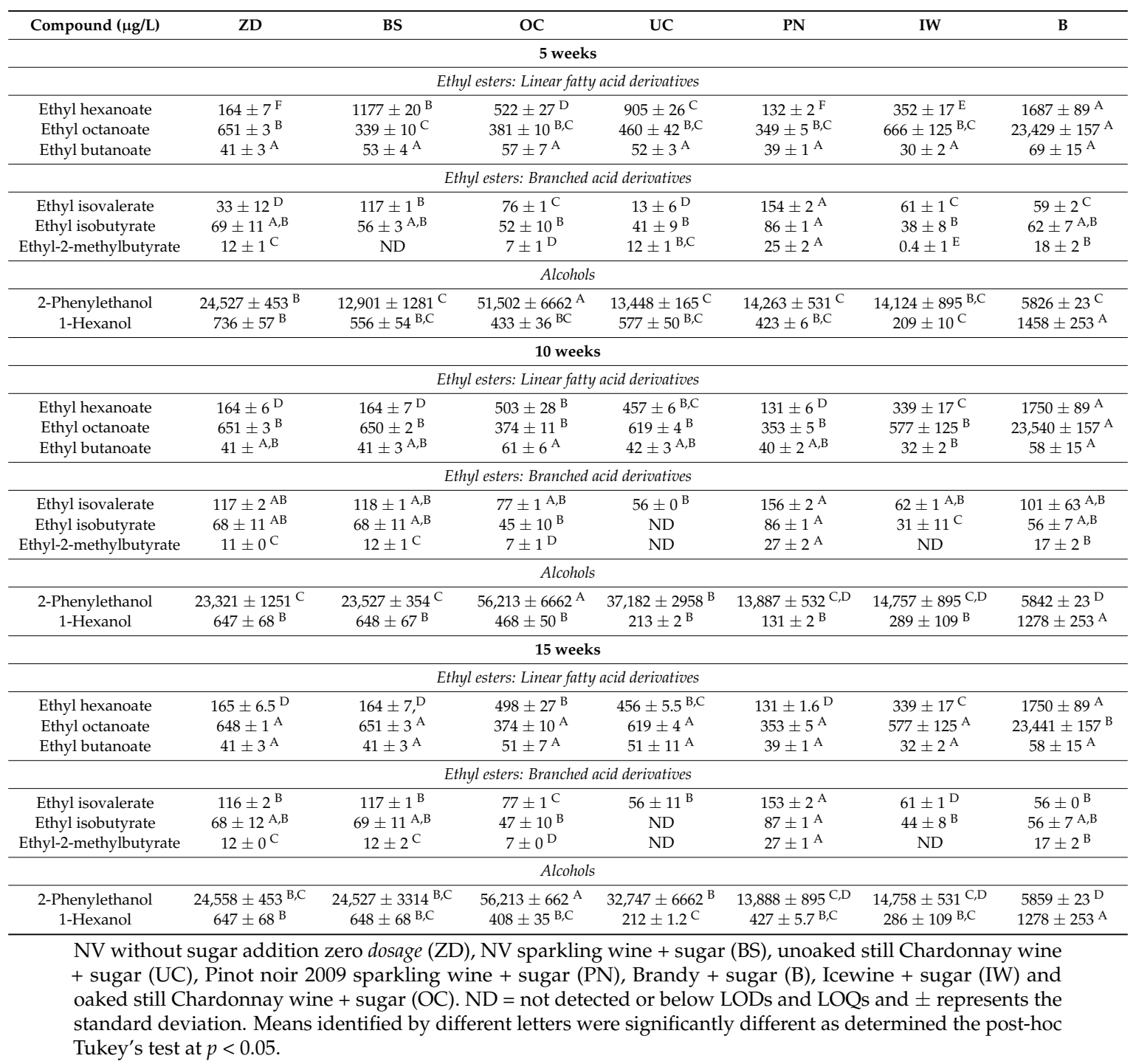

\subsection{Ten Weeks Post-Disgorging}

By 10 weeks post-disgorging, there was little difference between BS and ZD, thereby indicating that the sugar had little impact on VOCs by this time (Table 5). However, between 5 and 10 weeks, BS increased in 2-phenylethanol, 1-hexanol, ethyl isobutyrate, ethyl-2-methylbutyrate and ethyl octanoate but decreased in concentrations of ethyl hexanoate and ethyl butanoate. It is evident that 2-Phenylethanol was lower in BS wines compared to ZD at 5 weeks though by 10 weeks was slightly higher in BS compared to ZD. ZD showed an increase in ethyl isovalerate between 5 and 10 weeks which BS lacked.

Ethyl ester concentrations at 10 weeks post-disgorging were within ranges found in previous studies that investigated VOCs in sparkling wines made from Spanish grape varieties [5]. Unlike the results at 5 weeks, by 10 weeks post-disgorging, concentrations of ethyl butanoate in the treatment wines was statistically significant $(p<0.05)$. This was likely due to the high concentration found in $\mathrm{B}$. The results of the other linear fatty acid derivatives were also statistically significant and at 10 weeks post-disgorging, B again, had the highest concentrations of ethyl hexanoate and ethyl octanoate. PN had the highest concentrations of branched acid derivatives by 10 weeks post-disgorging, but also the lowest concentrations of linear fatty acid derivatives. These results may be attributed to PN being the 
oldest sparkling wine used in our study, with the longest lees aging time and ethyl ester concentrations are known to change with extended lees aging [27]. The lowest concentration of ethyl butanoate was found in IW, which also had the lowest concentration at 5 weeks post-disgorging. There was a significant statistical difference in all VOCs $(p<0.05)$ at 10 weeks.

Regarding alcohols, the highest concentration of 2-phenylethanol was found in OC wines and the lowest was in B, similar to 5 weeks post-disgorging. The 1-hexanol concentrations at 10 weeks post-disgorging were statistically significant $(p<0.05)$ due to the high amount found in B.

\subsection{Post-Disgorging at 15 Weeks}

At 15 weeks there was little difference between the ZD and BS for any compounds studied likely due to sugar hydrolysis (Table 5). It is interesting to note that by 15 weeks the concentrations of VOCs in $\mathrm{ZD}$ and BS were similar to the Brut wine prior to sugar addition.

Ethyl hexanoate, ethyl octanoate and ethyl octanoate was found to be at the highest concentration in B and lowest in PN. Although there was not a statistically significant difference between wines for ethyl butanoate, Brandy has high ethyl ester concentrations and ethyl esters decline during sparkling wine lees aging. The Pinot noir wine used in the dosage was from the 2009 vintage so had spent 5 years aging on yeast lees which may account for the different amounts of ethyl hexanoate in the final sparkling wines at this stage. In ZD, BS and PN, all dosage solutions made from sparkling wines were found to have statistically similar concentrations of ethyl hexanoate.

Branched acid derivatives were at their highest in PN and all 3 VOCs were statistically significant $(p<0.05)$. IW had the were lowest ethyl isobutyrate and the lowest ethyl-2-methylbutyrate was found in OC. UC had the lowest 1-hexanol and B was found to have the highest concentration just as it was at 5 and 10 weeks post-disgorging. Additionally, B had the lowest concentration of 2-phenylethanol while OC had the highest in 2-phenylethanol. There were greater changes in VOCs between 5 and 10 weeks than between 10 and 15 weeks post-disgorging.

The PCA (Figure 2) at 15 weeks' post-disgorging shows that the 3 treatment wines that had dosage solutions made from sparkling wines (second fermentation in bottle) are placed in the positive sector. The BS and ZD wines are extremely similar due to their close proximity. Likewise, OC and UC are also close together but near to IW, and these 3 wines used still wines in the dosage solutions. The ethyl esters that dominated B wine are responsible for its position on the peripheral of the PCA. These results suggest that by 15 weeks post-disgorging, the production methods used to produce the wines in the dosage treatments influenced the differences in the VOC results.

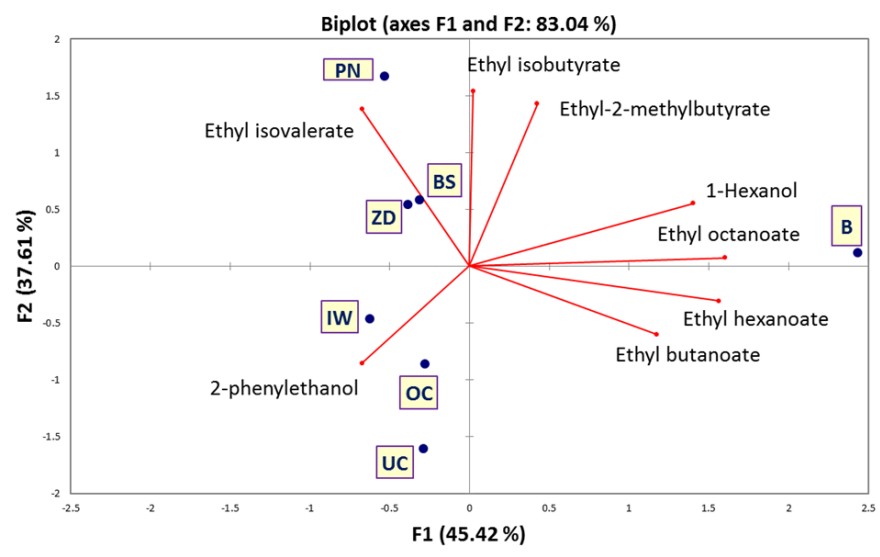

Figure 2. Principal Components Analysis (PCA) of the volatile aroma compounds (VOCs) in wines analysed at 15 weeks post-disgorging. NV sparkling wine without sugar addition = zero dosage (ZD), NV sparkling wine + sugar (BS), unoaked still Chardonnay wine + sugar (UC), Pinot noir 2009 sparkling wine + sugar (PN), Brandy + sugar (B), Icewine (IW) + sugar and oaked still Chardonnay wine + sugar (OC). 


\subsection{Odour Thresholds in Sparkling Wines}

An 'absolute' or odour detection threshold is the concentration range below which the odour or taste of a substance is not detectable and above which individuals with a normal sense of smell or taste can readily detect the presence of the substance [22,30]. For populations, the detection threshold is defined as the concentration at which $50 \%$ of the group can detect the odorant [30]. The concentrations of ethyl isobutyrate, and ethyl isovalerate and ethyl hexanoate at 5, 10 and 15 weeks post-disgorging were above their respective odour thresholds (Tables 1 and 5). By 15 weeks, concentrations of 1-hexanol were below its odour threshold for all wines and ethyl-2-methylbutyrate only exceeded its odour threshold in PN. Ethyl octanoate was below its odour threshold in PN, OC and IW. By 15 weeks the 2-phenylethanol concentrations were above its sensory threshold except for the B and PN wines. Ethyl butanoate was above its odour threshold according to Guth [11], which was calculated in $10 \%$ water/ethanol. Conversely, San Juan et al. [13] used a 10\% water/ethanol solution with a pH of 3.2 which resulted in its odour threshold increasing from $20 \mu \mathrm{g} / \mathrm{L}$ to $125 \mu \mathrm{g} / \mathrm{L}$. Therefore, as wine is an acidic medium, we found that ethyl butanoate was below its odour threshold ( $125 \mu \mathrm{g} / \mathrm{L})$ at all stages of analysis.

Another matrix effect within wine is referred to as an aroma buffer, and is caused by the numerous different VOCs found in wine. This aroma buffer effect describes how certain fusel alcohols, acids, esters and volatile phenols are not perceived separately within a wine [31]. This phenomenon is generally attributed to the presence of ethanol and a variety of fermentation-derived aromatic compounds. Since several compounds in alcoholic beverages are generally found coexisting as a result of fermentation, this causes the odour in question to be perceived as a mixture. Many aromatic compounds have similar odours and therefore, if one is lacking in concentration, the difference in the wine's profile would be negligible or undetectable by the average taster [31].

There are many factors that affect the concentrations of VOCs in sparkling wines including production techniques, grape variety, fining agents, yeast, ambient secondary fermentation temperature, type of sugar used during production, on-lees cellar storage temperature, liqueur d'expedition ingredients, oxygen ingress i.e., at disgorging, as well as closure type, $\mathrm{SO}_{2}$ levels, carbon dioxide levels $\left(\mathrm{CO}_{2}\right)$ and ethanol levels. The impact of $\mathrm{CO}_{2}$ on the perception of sugar and acidity in sparkling wine was confirmed by Thuillier [32]. Furthermore, increased $\mathrm{CO}_{2}$ concentrations in sparkling wines resulted in increased intensity of mouthfeel attributes, with the attributes burn, bite, carbonation/bubble pain, and foamy showing the greatest differences in wines and after-numbing and tingly showing the least [33]. However, the impact of $\mathrm{CO}_{2}$ and oxygen at disgorging on the concentrations of the VOCs studied is not known, yet both are likely to affect VOC concentrations as rising and collapsing bubbles act as continuous "portals" for volatile aromas in Champagne wine [34]. Additionally, carbonation has been reported to increase extremely volatile compounds i.e., ethyl butanoate, but not impact less volatile compounds, e.g., isoamyl acetate, due to a specific effect that is dependent on the physiochemical characteristics of each compound [35].

\section{Foam Analyses}

Protein concentrations, polysaccharides, alcohol levels, phenolic compounds and production processes all positively or negatively impact foam [2]. Due to different wine styles and production processes used to create the wines used as bases for the dosage solutions, we assessed the impact of the $20 \mathrm{~mL}$ dosage addition on the foam of the final sparkling wines. ZD had a foam height (FH) of $27.4 \mathrm{~cm}$ but the underlying wine volume in the glass, after the foam had dissipated, was $51 \mathrm{~mL}$ while BS foam height was $27.3 \mathrm{~cm}$ and underlying wine volume was $60 \mathrm{~mL}$. Additionally, ZD took 168 seconds to dissipate (FD), whereas BS sugar was far quicker and dissipated in just 50 seconds indicating that without the $8 \mathrm{~g} / \mathrm{L}$ of sugar addition ZD had better foam stability than BS. These dosages were NV wines, i.e., with the same wine in the dosage that was in the bottle, the only difference being sugar addition to BS. This difference in foam stability could be due to the increased viscosity of the wine with sugar addition that could have negatively impacted the foam. 
The wine with the next highest foam stability was PN at $76 \mathrm{~s}$, showing the benefit of using the oldest sparkling wine in the winery for dosage due to its positive impact on foam stability plus it had $27.1 \mathrm{~cm}$ of foam at pouring but $55 \mathrm{~mL}$ of underlying wine. OC wine took just $42 \mathrm{~s}$ for foam to dissipate and $\mathrm{FH}$ was $30 \mathrm{~cm}$ but it finished with the same volume of wine in the volumetric flask as PN. This may be due to a difference in compounds in Chardonnay wine compared to Pinot noir but were not analysed in this study, i.e., protein type and concentration. According to previous studies, Chardonnay sparkling wines were found to have a very small foam collar, a low foam height and short persistence, while Pinot noir sparkling wines exhibited higher height and longer persistence [36,37]. PN was the oldest sparkling wine and had extended time on yeast lees that could have released autolytic by-products such as yeast mannoproteins that are known to increase foamability [37]. Similar to the OC wines, B and IW had short foam dissipation times of $49 \mathrm{~s}$ and $43 \mathrm{~s}$, but resulted in $54 \mathrm{~mL}$ and $57 \mathrm{~mL}$ of underlying wine but an $\mathrm{FH}$ of $28 \mathrm{~cm}$ and $28.3 \mathrm{~cm}$ respectively. B had the highest total phenolics after dosage addition and highest alcohol which might have contributed to these results because ethanol and phenolic compounds both influence foam [2]. Although the optimal concentration of total phenolic compounds in sparkling wine required to impact foam is unknown, the low level of 2.1 A.U. suggests that their impact on foam is negligible so ethanol level might have been responsible for the lower foam in B. The UC wine took 64 seconds to dissipate, had $28.3 \mathrm{~cm}$ of foam and resulted in $59 \mathrm{~mL}$ of underlying wine. Further in-depth foam analysis using a Mosalux system was not suitable for our trial as it is only used on base wines or degassed sparkling wines. A Computer Assisted Viewing Equipment (CAVE) system or the FIZZeyeRobot (robotic pourer) would have provided further insight into the foam but were not available for use in this study [38,39].

\section{Sensory Difference Testing}

The "A-Not A" results were analysed using the Chi-squared test $\left(\chi^{2}\right)$ at a significance level of $5 \%$ and resulted in a significant statistical difference between the wine samples $(p=0.03)$ [16]. An R-index score of $50 \%$ means that wines are deemed identical and a score of $100 \%$ means the wines were completely different and therefore not deemed suitable for a difference test [19]. The $R$-index of $73 \%$ in our study for the " $\mathrm{A}$ " samples demonstrates a clear difference between the sensory control (OC) and the other treatment wines. Quantitation of attributes using descriptive sensory analysis would provide further information as to how the wines differ with regards to their sensory flavour characteristics.

There were clear differences between wines produced using different wine styles in the dosage solutions with an addition of $20 \mathrm{~mL}$ of dosage solution for a target residual sugar level of $8 \mathrm{~g} / \mathrm{L}$. From 5 to 15 weeks, higher alcohols were more affected by sugar additions than ethyl esters except for ethyl hexanoate, although some initial differences in volatile aroma compounds (VOCs) were observed in the zero-dosage wine compared to the same wine without sugar addition (BS). However, these had vanished by 15 weeks post-disgorging and both had similar concentrations of VOCs. Further investigation into higher sugar concentrations in traditional method sparkling wines may result in greater differences than observed in our study. These results provide evidence to wineries of the need to withhold sparkling wines from release immediately after disgorging and until wines reach equilibrium. $\mathrm{CO}_{2}$ impacts aroma detection in sparkling wines but as foam subsides in the glass, its presence or absence within sensory threshold ranges become more noticeable. Therefore, future research should involve additional families of VOCs, i.e., aldehydes, fatty acids, as well as descriptive sensory analysis every six months post-disgorging. A range of sugar levels in the same wines as well as blends of wine styles in the dosage solutions necessitates further investigation with regards to their influence on foam and sensory characteristics. Our study did not specifically separate the influence of $\mathrm{CO}_{2}$ from sugar addition effects, thus further studies could focus on the combined influence of $\mathrm{CO}_{2}$ and sugar on volatile aroma compounds. Future research could include in-depth analysis of residual enzymes from yeast cell lyses. Results could conceivably be used to characterise sparkling wines that have been produced using dosage solutions made using wines from a range of diverse production methods. 
Supplementary Materials: The following are available online at http://www.mdpi.com/2306-5710/3/1/7/s1, Table S1: Chemical composition of ZD sparkling wines: 5 and 10 weeks post-disgorging, Table S2: Chemical composition of BS sparkling wines: 5 and 10 weeks post-disgorging, Table S3: Chemical composition of OC sparkling wines: 5 and 10 weeks post-disgorging, Table S4: Chemical composition of UC sparkling wines: 5 and 10 weeks post-disgorging, Table S5: Chemical composition of PN sparkling wines: 5 and 10 weeks post-disgorging, Table S6: Chemical composition of IW sparkling wines: 5 and10 weeks post-disgorging, Table S7: Chemical composition of B sparkling wines: 5 and 10 weeks post-disgorging.

Acknowledgments: The authors wish to extend their gratitude to the Natural Sciences and Engineering Research Council (NSERC) of Canada for funding through the Engage programme, to Trius Winery for their in-kind contributions and to the Cool Climate Oenology and Viticulture Institute (CCOVI), Brock University, Ontario, Canada. The authors would like to thank Esther Onguta for assisting with the sensory and foam analysis, and Gary Pickering for his data interpretation assistance.

Author Contributions: Belinda Kemp conceived the idea for the study, designed the experiment, carried out the foam analysis, carried out the sensory analysis and sensory data analysis, and wrote the majority of this paper. Casey Hogan carried out all the standard chemical analyses and volatile aroma analyses. Shufen Xu assisted with the volatile aroma development method and wrote the HS-SPME-GC-MS methods section of the paper. Lisa Dowling assisted with the foam analysis, analysed the digital data and contributed to writing the paper. Debbie Inglis was the Principal Investigator, bringing all the researchers together with the industry partner, overseeing the research design and the main supervisor for Casey Hogan, contributed to writing the paper and is the Director of the Cool Climate Oenology and Viticulture Institute (CCOVI).

Conflicts of Interest: The authors declare no conflict of interest.

\section{Abbreviations}

The following abbreviations are used in this manuscript:

IS Internal standard

NV Non-vintage wine produced from a selection of base wines from a range of years

VOCs Volatile aroma compounds

\section{References}

1. Kemp, B.; Alexandre, H.; Robillard, B.; Marchal, R. Review: Effect of production phase on bottle-fermented sparkling wine quality. J. Agric. Food Chem. 2015, 63, 19-38. [CrossRef] [PubMed]

2. Bosch-Fusté, J.; Sartini, E.; Flores-Rubio, C.; Caixach, J.; Lopez-Tamames, E.; Buxaderas, S. Viability of total phenol index value as a quality marker of sparkling wines, "cavas". Food Chem. 2009, 114, 782-790. [CrossRef]

3. Jackson, R. Specific and Distinctive Wine Styles. In Wine Science: Principles and Practices, 4th ed.; Academic Press: San Diego, CA, USA, 2014; p. 714.

4. Martin, N.; Minard, A.; Brun, O. Sweetness, sourness, and total taste intensity in Champagne wine. Am. J. Enol. Vitic. 2002, 53, 6-13.

5. Pérez-Magariño, S.; Ortgea-Heras, M.; Bueno-Herrera, M.; Martỉnez-Lapuente, L.; Guadalupe, Z.; Ayestarán, B. Grape variety, aging on lees and aging in bottle after disgorging influences on volatile composition and foamability of sparkling wines. LWT-Food Sci. Technol. 2015, 61, 47-55. [CrossRef]

6. Buxaderas, S.; Lopez-Tamames, E. Managing the quality of sparkling wines. In Managing Wine Quality, 1st ed.; Reynolds, A., Ed.; Woodhead Publishing Ltd.: Cambridge, UK, 2010; pp. 553-588.

7. Iland, P.; Bruer, N.; Wilkes, E. Chemical Analysis of Grapes and Wine: Techniques and Concepts, 2nd ed.; Patrick Iland Wine Promotions: Adelaide, Australia, 2004.

8. Nurgel, C.; Pickering, G.; Inglis, D. Sensory and chemical characteristics of Canadian Icewines. J. Sci. Food Agric. 2004, 84, 1675-1684. [CrossRef]

9. Botezatu, A.; Kemp, B.; Pickering, G. Chemical and sensory evaluation of silicone and polylactic acid-based remedial treatments for elevated methoxypyrazine levels in wine. Molecules 2016, 21, 1238. [CrossRef] [PubMed]

10. Etiévant, P.X. Wine. In Volatile Compounds in Food and Beverages. Food Science and Technology; Maarse, H., Ed.; Marcel Dekker Inc.: New York, NY, USA, 1991; Chapter 14; pp. 483-546.

11. Guth, H. Quantitation and sensory studies of character impact odorants of different white wine varieties. J. Agric. Food Chem. 1997, 45, 3027-3032. [CrossRef] 
12. Ferreira, V.; Lopez, R.; Cacho, J.F. Quantitive determination of the odorants of young red wines from different grape varieties. J. Sci. Food Agric. 2000, 80, 1659-1667. [CrossRef]

13. San Juan, F.; Ferreira, V.; Cacho, J.; Escudero, A. Quality and aromatic sensory descriptors (mainly fresh and dried fruit character) of Spanish red wines can be predicted from their aroma-active chemical composition. J. Agric. Food Chem. 2011, 59, 7916-7924. [CrossRef] [PubMed]

14. Lynch, D.M.; Bamford, C.W. Measurement and characterization of bubble nucleation in beer. J. Food Sci. 2002, 67, 2696-2701. [CrossRef]

15. Curioni, A.; Vincenzi, S.; Bona, S. Some results on the evaluation of the foam behaviour for sparkling wines. In Proceedings of the 3rd International Symposium/33rd International CAVA Congress, 3rd Oenoviti International Symposium, Cava Challenges, Subirats, Spain, 20 May 2015.

16. Jeonga, Y.N.; Kanga, B.A.; Jeonga, M.J.; Songa, M.J.; Hautusb, M.J.; Leea, H.S. Sensory discrimination by consumers of multiple stimuli from a reference: Stimulus configuration in A-Not AR and constant-ref. duo-trio superior to triangle and unspecified tetrad? Food Qual. Preference 2015, 47, 10-22. [CrossRef]

17. Kim, M.-A.; Chae, J.-E.; van Hout, D.; Lee, H.-S. Discriminations of the A-Not A difference test improved when "A" was familiarized using a brand image. Food Qual. Preference 2012, 23, 3-12. [CrossRef]

18. Van Hout, D.; Hautus, M.J.; Lee, H.S. Investigation of test performance over repeated sessions using signal detection theory: Comparison of three non-attribute-specified difference tests 2-AFCR, A-NOT A and 2-AFC. J. Sens. Stud. 2011, 26, 311-321. [CrossRef]

19. Kemp, S.E.; Hollowood, T.; Hort, J. Sensory test methods. In Sensory Evaluation: A Practical Handbook; Wiley-Blackwell Publishing: Chichester, UK, 2009; pp. 80-83.

20. Lee, H.-S.; van Hout, D.; Hautus, M.J. Comparison of performance in the A-Not A, 2-AFC, and same-different tests for the flavor discrimination of margarines: The effect of cognitive decision strategies. Food Qual. Preference 2007, 18, 920-928. [CrossRef]

21. Stefenon, C.A.; de Martini-Bonesi, C.; Mazarotto, V.; Barabé, D.; Agostini, F.; Perin, J.; Serafini, L.L.; Vanerlinde, R. Sugar levels in Charmat sparkling wines can affect quality and resveratrol levels. Redox Rep. Commun. Free Radic. Res. 2010, 15, 1-6.

22. American Society of Testing and Materials (ASTM). Standard Practice E679. Determination of Odor and Taste Thresholds by a Forced-Choice Ascending Concentration Series Method of Limits; American Society of Testing and Materials: Philadelphia, PA, USA, 1979.

23. Ganss, S.; Kirsch, F.; Winterhalter, P.; Fischer, U.; Schmarr, H.G. Aroma changes due to second fermentation and glycosylated precursors in Chardonnay and Riesling sparkling wines. J. Agric. Food. Chem. 2011, 59, 2524-2533. [CrossRef] [PubMed]

24. González-Marco, A.; Jiménez-Moreno, N.; Ancín-Azpilicueta, C. Concentration of volatile compounds in Chardonnay wine fermented in stainless steel tanks and oak barrels. Food Chem. 2008, 108, 213-219. [CrossRef]

25. Tsakiris, A.; Kallithraka, S.; Kourkoutas, Y. Grape brandy production, composition and sensory evaluation. J. Sci. Food. Agric. 2014, 94, 404-414. [CrossRef] [PubMed]

26. Francioli, S.; Guerra, M.; Lopez-Tammames, E.; Guadayoi, J.M.; Caixach, J. Aroma of Sparkling Wines by Headspace/Solid Phase Microextraction and Gas Chromatography/Mass Spectrometry. Am. J. Enol. Vitic. 1999, 50, 404-408.

27. Riu-Aumatell, M.; Bosch-Fusté, J.; Lopez-Tamames, E.; Buxaderas, S. Development of volatile compounds of cava (Spanish sparkling wine) during long ageing time in contact with lees. Food Chem. 2006, 95, 237-242. [CrossRef]

28. Bosch-Fusté, J.; Riu-Aumatella, M.; Guadayol, J.M.; Caixach, J.; López-Tamames, E.; Buxaderas, S. Volatile profiles of sparkling wines obtained by three extraction methods and gas chromatography-mass spectrometry (GC-MS) analysis. Food Chem. 2007, 105, 428-435. [CrossRef]

29. Coelho, E.; Coimbra, M.A.; Nogueria, J.M.F.; Rocha, S.M. Quantification approach for assessment of sparkling wine volatiles from different soils, ripeness stages, and varieties by stir bar sorptive extraction with liquid desorption. Anal. Chim. Acta 2009, 635, 214-221. [CrossRef] [PubMed]

30. Cliff, M.A.; Pickering, G.J. Determination of odour detection thresholds for acetic acid and ethyl acetate in ice wine. J. Wine Res. 2006, 17, 45-52. [CrossRef] 
31. Escudero, A.; Gogorza, B.; Melús, M.; Ortín, N.; Cacho, J.; Ferreira, V. Characterization of the aroma of a wine from Maccabeo. Key role played by compounds with low odour activity values. J. Agric. Food Chem. 2004, 52, 3516-3524. [CrossRef] [PubMed]

32. Thuillier, B. Influence of $\mathrm{CO}_{2}$ in Organoleptic Qualities of Champagnes. Experiments and Methodology Developments. Ph.D. Thesis, University of Reims, Reims, France, 2007.

33. McMahon, K.M. Sensory and Analytical Assessment of Sparkling Wines. Ph.D. Thesis, Washington State University, Washington, DC, USA, 2016.

34. Liger-Belair, G.; Cilindre, C.; Gougeon, R.D.; Lucio, M.; Gebefügi, I.; Jeandet, P.; Schmitt-Kopplin, P. Unraveling different chemical fingerprints between a champagne wine and its aerosols. Proc. Natl. Acad. Sci. USA 2009, 106, 16545-16549. [CrossRef] [PubMed]

35. Pozo-Bayón, M.A.; Santos, M.; Martin-Álvarez, P.J.; Reineccius, G. Influence of carbonation on aroma release from liquid systems using an artificial throat and a proton transfer reaction-mass spectrophotometric technique (PTR-MS). Flavour Fragr. J. 2009, 24, 226-233. [CrossRef]

36. Marchal, R.; Tabary, L.; Valade, M.; Moncomble, D.; Viaux, L.; Robillard, B.; Jeandot, P. Effects of Botrytis cinerea infection on Champagne wine foaming. J. Sci. Food Agric. 2001, 81, 1371-1378. [CrossRef]

37. Herrero, P.; Sáenz-Navajas, P.; Culleré, L.; Ferreira, V.; Chatin, A.; Chaperon, V.; Litoux-Desrues, F.; Escudero, A. Chemosensory characterization of Chardonnay and Pinot Noir base wines of Champagne. Two very different varieties for a common product. Food Chem. 2016, 207, 239-250. [CrossRef] [PubMed]

38. Cilindre, C.; Liger-Belair, G.; Villaume, S.; Jeandot, P.; Marchal, R. Foaming properties of various Champagne wines depending on several parameters: Grape variety, aging, protein and $\mathrm{CO}_{2}$ content. Anal. Chim. Acta 2010, 660, 164-170. [CrossRef] [PubMed]

39. Condé, B.; Fuentes, S.; Caron, M.; Xiao, D.; Collmann, R.; Howell, K. Development of a robotic and computer vision method to assess foam quality in sparkling wines. Food Control 2017, 71, 383-392. [CrossRef]

(C) 2017 by the authors; licensee MDPI, Basel, Switzerland. This article is an open access article distributed under the terms and conditions of the Creative Commons Attribution (CC-BY) license (http://creativecommons.org/licenses/by/4.0/). 